\title{
Hydrothermal Synthesis of Hydrated Zinc Oxide Nanoparticles and its Characterization +
}

\author{
K. SURESH BABU and V. NARAYANAN* \\ Department of Inorganic Chemistry, University of Madras, \\ Guindy Campus, Chennai-600025, India \\ vnnara@yahoo.co.in
}

Received 21 January 2013 / Accepted 15 February 2013

\begin{abstract}
Hydrated zinc oxide nanoparticles were successfully prepared by hydrothermal method using zinc acetate and sodium hydroxide as the zinc and hydroxide sources along. The synthesized zinc oxide nanoparticles were characterized by XRD, FTIR and SEM in order to confirm the phase purity and morphology of the sample. Zinc oxide nanoparticles exhibit hexagonal wurtzite structure, which was revealed by the XRD analysis. The synthesized hydrated zinc oxide was used to modify glassy carbon electrode (GCE). The electrochemical property of the modified electrode ( $\mathrm{ZnO} / \mathrm{GCE}$ ) was tested in a $\mathrm{pH}$ 7.4 phosphate buffer solutions (PBS) by cyclic voltammetry (CV). There is no peak observed in the voltammogram which indicated that the material can be used as an electrochemical sensor.
\end{abstract}

Keywords: ZnO, Nanoparticles, X-ray diffraction, Cyclic voltammetry

\section{Introduction}

Zinc oxide $(\mathrm{ZnO})$ is a wide band gap $(3.37 \mathrm{eV})$ semiconductor with a large exciton binding energy $(60 \mathrm{mV})$ and one of the most widely used and studied functional oxides ${ }^{1,2}$. Zinc oxide readily forms into noncentral symmetric wurtzite nanocrystal structures with self-polarized crystal surfaces. The thermodynamically stable crystallographic faces of $\mathrm{ZnO}$ include a polar-terminated (001) face and nonpolar low-symmetry (100) faces. The low- symmetry surfaces are more stable than the polar face, leading to faster growth along the polar surface. As a result, a variety of one-dimensional (1D) $\mathrm{ZnO}$ nano-structures including nanorods/ nanowires, nanobelts, nanorings and other hierarchical nanostructures can be readily synthesized and these materials have been examined for applications in photovoltaic energy conversion, optics, optoelectronics, catalysis, piezoelectric systems, photocatalysts, chemical sensors and solar cells ${ }^{3-7}$.

In this study, we have reported the synthesis of $\mathrm{ZnO}$ nanoparticles using hydrothermal method and characterized its structural, morphological properties. Additionally we have performed the electrochemical activity of the synthesized $\mathrm{ZnO}$. 


\section{Experimental}

Zinc acetate dihydrate $\left(\mathrm{Zn}\left(\mathrm{CH}_{3} \mathrm{COO}\right)_{2} \cdot 2 \mathrm{H}_{2} \mathrm{O}\right)$ and sodium hydroxide were purchased from Qualigens. Double distilled water was used as the solvent throughout the experiment.

\section{Characterization methods}

The crystal structure of $\mathrm{ZnO}$ nanoparticles was analyzed by a Rich Siefert 3000 diffractometer with $\mathrm{Cu}-\mathrm{K} \alpha_{1}$ radiation $(\lambda=1.5406 \AA)$. FT-IR spectrum of the $\mathrm{ZnO}$ was recorded on Schimadzu FT-IR 8300 series instrument by using potassium bromide pellets. The morphology of the materials was analyzed by SEM HITACHI SU6600 scanning electron microscopy respectively. The electrochemical experiments were performed on a CHI 600A electrochemical instrument using the as-modified electrode and bare GCE as working electrode, a platinum wire was the counter electrode and saturated calomel electrode (SCE) was the reference electrode.

\section{Synthesis of $\mathrm{ZnO}$ nanoparticles}

$0.070 \mathrm{~g}$ of $\mathrm{Zn}\left(\mathrm{CH}_{3} \mathrm{COO}\right)_{2} \cdot 2 \mathrm{H}_{2} \mathrm{O}$ and $0.400 \mathrm{~g}$ of $\mathrm{NaOH}$ were dissolved into $40 \mathrm{~mL}$ of distilled water. After the mixture was magnetically stirred for 20 min and this solution was transferred into a $50 \mathrm{~mL}$ Teflon-lined stainless steel autoclave. It was then sealed and maintained at $180{ }^{\circ} \mathrm{C}$ for $2 \mathrm{~h}$. After slowly being cooled to room temperature, obtained powders were collected by centrifugation and washed with distilled water and absolute ethanol. The powders were finally dried at $60{ }^{\circ} \mathrm{C}$ for $12 \mathrm{~h}$.

\section{Electrode modification}

Ultrasonically dispersed $\mathrm{ZnO}$ nanopowder in $5 \mathrm{~mL}$ of water was drop coated onto the GCE and dried at room temperature. CV's were run in electrochemical cell containing $50 \mathrm{~mL}$ of $0.1 \mathrm{M} \mathrm{KOH}$ in presence of SCE as a reference electrode and Pt wire as counter electrode.

\section{Results and Discussion}

\section{Structural characterization}

XRD patterns of the $\mathrm{ZnO}$ nanoparticles prepared by hydrothermal method is shown in Figure 1, which indicates the $\mathrm{ZnO}$ has hexagonal wurtzite phase structure The peak and relative intensities obtained for the $\mathrm{ZnO}$ match with the literature values ${ }^{8}$. There was no characteristic peaks of impurity were observed. The average grain size of $\mathrm{ZnO}$ is determined using Scherrer relation ${ }^{9}$ and it was found to be around $72 \mathrm{~nm}$.

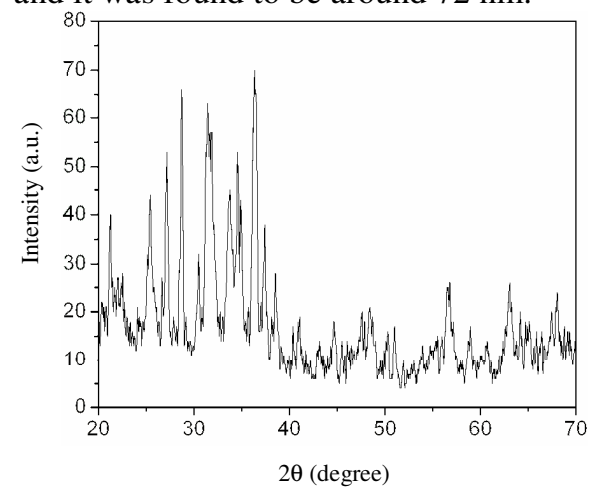

Figure 1. XRD pattern of $\mathrm{ZnO}$ nanoparticles 
FT-IR spectrum of $\mathrm{ZnO}$ nanoparticles (Figure 2) showed significant absorption peaks at 3457 and $1598,452 \mathrm{~cm}^{-1}$. The absorption band at $452 \mathrm{~cm}^{-1}$ was assigned to $\mathrm{Zn}-\mathrm{O}$ stretching vibration ${ }^{10}$. The weak band near $1598 \mathrm{~cm}^{-1}$ is assigned to $\mathrm{H}-\mathrm{O}-\mathrm{H}$ bending vibration mode were presented due to the adsorption of moisture, when FTIR sample disks were prepared in an open air atmosphere. These observations provided the evidence for the presence of hydration in the structure ${ }^{11}$.

The SEM micrograph of the $\mathrm{ZnO}$ by hydrothermal method is shown in Figure 3. It can be seen that the particles adopt irregular morphology with different sized particle whose size is in the nm range. It is expected that the formation of agglomerates were purely due to the synthetic condition.

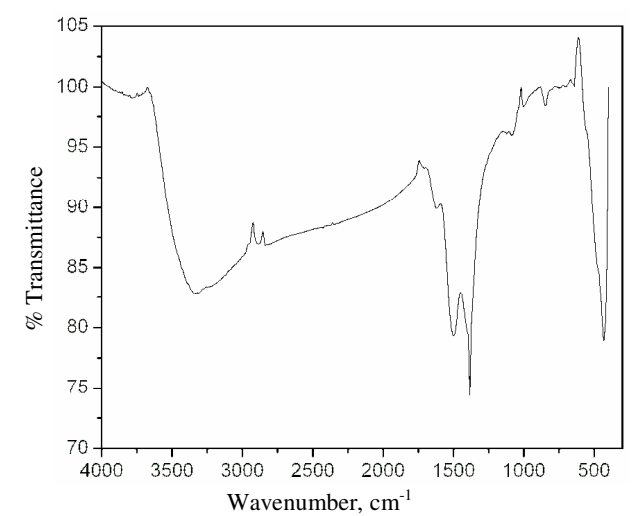

Figure 2. FT-IR spectrum of $\mathrm{ZnO}$ nanoparticles

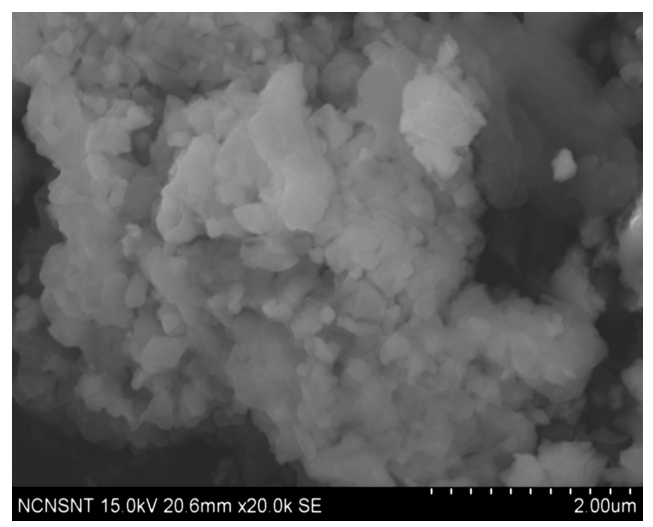

Figure 3. FESEM image of $\mathrm{ZnO}$ nanoparticles

The electrochemical behaviour of $\mathrm{ZnO} / \mathrm{GCE}$ was examined by cyclic voltammetry. Figure 4 shows the $\mathrm{CV}$ of bare and $\mathrm{ZnO} / \mathrm{GCE}$ in $0.1 \mathrm{M} \mathrm{KOH}$ as a supporting electrolyte. It can be seen that the $\mathrm{ZnO}$ is non-electroactive in the selected potential region. However, it shows enhanced peak current than the bare GCE which indicated that the modified electrode can be further used for the determination of biologically important molecules.

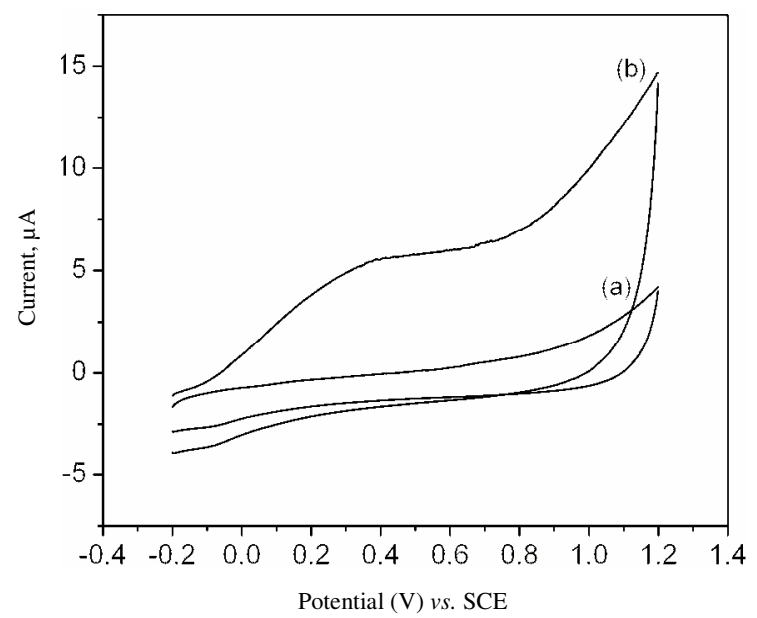

Figure 4. $\mathrm{CV}$ of (a) bare (b) $\mathrm{ZnO} / \mathrm{GCE}$ in $0.1 \mathrm{M} \mathrm{KOH}$ at $50 \mathrm{mV} / \mathrm{s}$ 


\section{Conclusion}

The $\mathrm{ZnO}$ nanoparticles were successfully prepared by hydrothermal method. FT-IR analysis confirms the formation of the $\mathrm{Zn}-\mathrm{O}$ bond in the $\mathrm{ZnO}$ nanoparticles. The XRD confirms the crystal structure and phase purity of the sample. The SEM of $\mathrm{ZnO}$ nanoparticles shows the spherical agglomerated particles. The electrochemical property of the $\mathrm{ZnO}$ nanoparticles modified GCE was investigated by cyclic voltammetry. The results conclude that the $\mathrm{ZnO}$ nanoparticles will have potential application in the electrochemical sensor.

\section{References}

1. Wang Z L, Materials Today, 2004, 7, 26-33.

2. Rao C N R and Govindaraj A, in Nanotubes and Nanowires, Kroto H, O'Brien P and Craighead H, Eds., The RSC Nanoscience and Nanotechnology Series, Royal Society of Chemistry, London, UK, 2005.

3. Topoglidis E, Cass A E G, O'Regan B and Durrant J R, J Electroanalytical Chem., 2001, 517, 20-27.

4. Hames Y, Alpaslan Z, K“osemen A, San S E and Yerli Y, Solar Energy, 2010, 84, 426-431.

5. Jun W, Changsheng X, Zikui B, Bailin Z, Kaijin H and Run W, Mater Sci Eng B, 2002, 95, 157-161.

6. Sharma P, Sreenivas K and Rao K V, J Appl Phy., 2003, 93, 3963-3970.

7. Kamat P V, Huehn R and Nicolaescu R, J Phys Chem B, 2002, 106, 788-794.

8. Zhou J, Zhao F, Wang Y, Zhang Y and Yang L, J Luminescence, 2007, 122-123, 195-197.

9. Cullity B D, Elements of X-Ray Diffraction, Addison-Wesley, Reading, Mass, USA, $3^{\text {rd }}$ Edition, 1967.

10. Hong R Y, Li J H, Chen L L, Liu D Q, Li H Z, Zheng Y and Ding J, Powder Technology, 2009, 189(3), 426-432.

11. Xiong G, Pal U, Serrano J G, Ucer K B and Williams R T, Phys Stat Sol (c), 2006, 3(10), 3577-3581. 